\title{
Psikologi Peluang Kewirausahaan: Proses Kognitif Pengusaha Startup Digital dalam Opportunity Recognition
}

\author{
Entrepreneurship Opportunity Psychology: Cognitive Process \\ Digital Startup Entrepreneurs in Opportunity Recognition
}

\author{
Sadida Fatin Aruni ${ }^{1}$ E Rahmat Hidayat ${ }^{2}$
}

Fakultas Psikologi Universitas Gadjah Mada

\begin{abstract}
Initial psychological studies on entrepreneurship are focused on the personal characteristics of the entrepreneurs. However, conclusions from more than 30 years of research indicate that there are no special personality characteristics of entrepreneurs and non-entrepreneurs. In essence, the heart of entrepreneurship lies in the ability to recognize an opportunity. Opportunity recognition is a mechanism that happens in an individual's cognitive process. Therefore, this study intended to reveal the cognitive processes that take place when entrepreneurs, in particular, the founders of digital startups, in the identification of entrepreneurial opportunities. This research use thinks aloud protocol method with protocol analysis. Based on this research, we found that in the process of opportunity recognition, entrepreneurs focus their cognitive efforts on the market (demand) and technology (supply) as well as build relationships and meaningful patterns in these two aspects through structural relationship processing. This study provides an in-depth description of the cognitive processes that occur when entrepreneurs recognize entrepreneurial opportunities through structural alignment processes.
\end{abstract}

Keywords: cognitive process; digital startup; entrepreneurship; opportunity recognition

\begin{abstract}
Abstrak. Kajian awal psikologis pada kewirausahaan difokuskan pada karaktersitik personal pengusaha. Akan tetapi, kesimpulan dari penelitian selama puluhan tahun menunjukkan bahwa tidak ada karakteristik kepribadian khusus dari pengusaha dan non-pengusaha. Pada dasarnya, jantung dari kewirusahan adalah orientasi dalam melihat peluang. Peluang merupakan hal yang dipersepsikan oleh individu sehingga tercakup dalam ranah kajian kognitif. Oleh karena itu, penelitian ini bermaksud mengungkap proses kognitif yang berlangsung ketika pengusaha khususnya founders startup digital dalam identifikasi peluang kewirausahaan. Penelitian ini menggunakan metode think aloud protocol dengan protocol analysis. Dari penelitian ini ditemukan bahwa dalam proses identifikasi peluang, pengusaha memfokuskan cognitive effort mereka pada pasar (demand) dan teknologi (supply) sekaligus serta membangun hubungan dan pola-pola bermakna pada dua aspek tersebut melalui pemrosesan structural relationship. Penelitian ini memberikan deskripsi mendalam mengenai proses kognitif yang terjadi ketika pengusaha melakukan opportunity recognition melalui proses structural alignment.
\end{abstract}

Kata kunci: pengusaha; proses kognitif; rekognisi peluang kewirausahan; startup digital

Menurut PBB, setidaknya suatu negara dapat maju apabila terdapat $2 \%$ pengusaha dari total penduduk negara tersebut
(Buchari, 2009). Berdasarkan data Kementerian Koperasi dan Usaha Kecil Menengah jumlah pengusaha di Indonesia

\footnotetext{
${ }^{1}$ Korespondensi mengenai artikel ini dapat melalui: sadidasfa@gmail.com; r.hidayat@ugm.ac.id
} 
tercatat hanya $1,56 \%$ dari total penduduk Indoneisa (Pradana, 2013). Ditambah lagi menurut Kepala Badan Pusat Statistik, jumlah pengangguran yang berasal dari lulusan perguruan tinggi tahun 2016 justru meningkat dari 5,34\% menjadi 6,22\% (Sawitri, 2016). Oleh karena itu, perlu adanya perhatian khusus terhadap pengembangan pengusaha di Indonesia khususnya pengusaha pemula demi mendorong pertumbuhan ekonomi Indonesia yang optimal.

Beberapa tahun terakhir, pengembangan pengusaha tidak terlepas dari perkembangan dunia startup. Bahkan, Indonesia merupakan negara dengan jumlah startup terbanyak di Asia Tenggara (Amalia, 2016). Menurut U.S Small Bussiness Administration, startup adalah sebuah bisnis yang berorientasi pada teknologi dan memiliki potensi perkembangan yang tinggi (U.S Small Business Administration, 2016). Demi menjaga ekosistem perkembangan startup yang semakin baik di Indonesia, pemerintah pun melakukan berbagai langkah positif. Dukungan pemerintah ini tampak dari didirikannya Badan Ekonomi Kreatif (Bekraf) yang akan menangani industri kreatif dan digital. Selain itu, Presiden Jokowi pun sempat mengunjungi Silicon Valley yang merupakan markas bagi startup terbaik dunia, demi mendukung perkembangan startup Indonesia (Ryza, 2016). Ditambah lagi, Kementrian Komunikasi dan Informatika telah secara resmi meluncurkan Gerakan Nasional 1000 Startup Digital. Menteri Kominfo Rudiantara menjabarkan bahwa industri digital akan sangat berpengaruh terhadap GDP Indonesia (Kominfo.go.id, 2016).

Wirausahawan pada perusahaanperusahaan baru ini membuat kontribusi yang signifikan pada perkembangan ekonomi, baik secara langsung maupun karena mereka menstimulasi kompetitorkompetitor mereka yang telah mapan (Acs \& Audretsch, 2005). Pengusaha ini merupakan pengusaha muda yang telah berhasil mengembangkan bisnisnya. Perbedaan aspirasi kalangan anak muda dan aktivitas bisnis orang dewasa menjadi kajian penting pada kewirausahaan. Akan tetapi, masih sangat sedikit penelitian yang menggali pengusaha muda, bahkan kebanyakan reviu pada kajian kewirausahaan tidak menyebutkan topik pengusaha muda sama sekali (Geldhof, et al., 2014)

Kewirausahaan atau entrepreneurship telah dianggap sebagai mesin pembangun ekonomi dan sosial di seluruh dunia. Pengusaha menjadi sosok yang teramat esensial, mengutip pernyataan Acs \& Audretsch (2005) pengusaha dianggap sebagai pemain paling penting dalam ekonomi modern.

\section{Peluang}

Seiring dengan berkembangnya pembahasan mengenai kewirausahaan, proses mengidentifikasi peluang dianggap merepresentasikan perilaku kewirausahaan yang paling khas dan mendasar (Venkataraman 1997; Shane, 2000; Gaglio \& Katz, 2001; George, Parida, Lahti, \& Wincent, 2016). Peluang atau opportunity dapat diartikan sebagai serangkaian tindakan untuk mendapatkan keuntungan dari perubahan yang terjadi (Gregoire, Barr, \& Shepherd, 2010). Shane (2003) mendefinisikan peluang kewirausahaan sebagai sebuah situasi ketika individu dapat menciptakan sebuah new means-ends framework atau kerangka baru mengenai sarana atau tindakan dalam mencapai sebuah tujuan, untuk mengembangkan sumber daya yang ada, yang dipercaya dapat menghasilkan keuntungan. 
Pada dasarnya, peluang berasal dari perubahan-perubahan, baik perubahan pengetahuan, perubahan pada perilaku dari pelaku ekonomi maupun perubahan skala besar pada lingkungan makro seperti perkembangan teknologi (Shane, 2003; Gregoire et al., 2010). Dengan perubahan dari perkembangan teknologi yang begitu melejit beberapa dekade terakhir, hal ini tentunya menjadi landasan munculnya peluang perkembangan startup digital yang telah disebutkan sebelumnya. Keadaan ini memunculkan pertanyaan, bagaimana pengusaha-pengusaha startup merekognisi peluang-peluang tersebut sedangkan masih banyak anak muda yang tidak mampu merekognisi peluang? Hal ini menjadi sebuah pertanyaan esensial ditengah kebutuhan Indonesia akan pengusaha.

\section{Model psikologis peluang}

Kajian awal psikologis pada kewirausahaan difokuskan pada karakterisitik personal pengusaha tersebut (personality of entrepreneur) atau kepribadian khusus pengusaha (Shaver \& Scott, 1991). Akan tetapi secara mengejutkan, peneliti-peneliti tidak dapat menunjuk perbedaan jelas antara pengusaha dan individu lain pada dimensi kepribadian yang relevan (Gartner, 1989; Drucker, 1985; Shaver \& Scott, 1991; Busenitz \& Barney, 1997; Baron 1998). Kajian terbaru menyebutkan bahwa proses kognitif merupakan salah satu perspektif yang dapat digunakan untuk menjawab pertanyaan tersebut (Baron, 1998; Baron, 2004; Krueger, 2003; Gregoire et al., 2010). Hal ini didukung pandangan Krueger (2003) yang menyatakan bahwa jantung dari kewirusahan adalah orientasi dalam melihat peluang, maka darimanakah persepsi tentang peluang ini muncul? Peluang pada dasarnya merupakan hal yang dipersepsikan oleh individu sehingga tercakup dalam ranah kajian kognitif. Oleh karena itu, memahami infrastruktur kognitif yang mendasari aktivitas kewirausahaan dalam hal ini adalah peluang, akan menyediakan perspektif yang lebih kaya tentang cara memilihara dan menumbuhkan kewirausahaan.

\section{Pattern recognition}

Dalam konsep pattern recognition individu membangun prototype yaitu sebuah cognitive framework yang mere- presentasikan anggota paling khas dari sebuah kategori. Secara sederhana, prototype memberikan panduan pada individu yang memilikinya untuk menyadari hubungan diantara kejadian yang beragam serta mendeteksi pola bermakna atau pattern recognition pada hubungan tersebut (Whittlesea, 1997). Mengaplikasikan model prototype dalam opportunity recognition Baron (2006) menyatakan bahwa pengusaha membandingkan kejadian yang terlihat independen seperti perubahan teknologi dan keadaan pasar dan mendeteksi adanya pola yang merujuk pada peluang kewirausahaan.

\section{Structural alignment}

Penelitian Gregoire et al., (2010) juga menunjukkan bahwa pengusaha mengunakan proses kognitif tertentu dalam startegi penalaran khususnya pada peran structural alignment. Peneliti kognitif menunjukkan bahwa mekanisme yang mendasari structural alignment memerankan peran penting tentang bagaimana individu memahami informasi baru, serta memengaruhi performa aktivitas yang membutuhkan level abstract reasoning yang tinggi seperti inovasi ilmiah, ide produk baru serta berbagai usaha kreatif lainnya (Holland, Holyoak, Nisbett, \& Thagard, 1986; Vosniadou dan Ortony, 1989; Dahl 
dan Moreau, 2002; Dunbar, 1993; Ward, 1995).

Proses alignment terdiri dari dua level, yaitu superficial features serta structural relationship (Gentner, 1983; 1989). Superficial features berkaitan dengan bagian dasar dari mental representation beserta atribut dan karakteristiknya (Gentner, Rattermann, Markman, \& Kotovsky, 1995). Sebaliknya, structural relation merujuk pada hubunganhubungan yang menyatukan perbedaan dari superficial features dalam representasi mental. Dari penelitian yang ada terdapat dua jenis strutural relationship, yaitu firstorder dan high order structural relationship. First order menunjukkan satu banding satu hubungan fungsional antara superficial features seperti efek langsung, sedangkan higher-order relationship menunjukkan hubungan yang lebih abstrak yaitu hubungan dari hubungan-hubungan yang telah ada seperti rantai sebab akibat, pernyataan tujuan serta peraturan kondisional (Gentner, 1989; Gentner Rattermann, \& Forbus, 1993; Holyoak, 1985).

Ketika stimulus merepresentasikan teknologi baru, pengusaha memproses stimulus tersebut dalam superficial features seperti siapa yang mengembangkan dan material yang digunakan. Setelah itu mereka menciptakan hubungan yang menggabungkan fitur-fitur yang berbeda tersebut melalui representasi mental structural alignment (Gregoire et al., 2010).

Penelitian ini akan memaparkan proses rekognisi peluang dari perspektif kognitif yang dianggap menjadi dasar proses kewirausahan. Proses kognitif tersebut menjadi penjelasan mengapa masih banyak anak muda Indonesia yang belum merekognisi peluang seperti pengusaha muda startup lainnya yang telah berhasil. Ditengah kebutuhan Indonesia akan pengusaha muda, penjelasan proses kognitif rekognisi peluang pengusaha muda yang masih sangat jarang dibahas pada literatur tentunya menjadi sangat penting.

\section{Metode}

\section{Subjek penelitian}

Partisipan penelitian adalah founder startup digital yaitu individu yang mendirikan sebuah startup, sehingga berperan penting pada identifikasi peluang. Satu dari lima partisipan merupakan mahasiswa semester akhir serta lima lainnya adalah fresh graduate.

\section{Metode penelitian}

Penelitian ini menggunakan think aloud protocol (Someran, Barnard, \& Sandberg, 1994) untuk mendapatkan data. Dalam metode think aloud protocols partisipan diminta terus berbicara, mengutarakan pikiran apapun yang terlintas sambil mengerjakan tugas yang diberikan. Proses ini tidak menggunakan interupsi atau suggestive prompts sehingga partisipan didorong untuk memberikan narasi dari proses berpikirnya serta menghindari interpretasi dari yang dia lakukan, partisipan hanya berkonsentrasi pada tugas yang diberikan.

\section{Instrumen penelitian}

Secara umum, penelitian ini menggunakan instrumen yang telah digunakan dalam penelitian Gregoire et al., (2010) yang merupakan deskripsi dua teknologi baru sebagai representasi perubahan teknologi. Stimulus pertama merupakan deskripsi teknologi dari NASA Self-Mastery and Regulation Training (SMART ${ }^{\mathrm{TM}}$ ) dan stimulus kedua merupakan teknologi dari MIT three dimensional printing (3DPTM). 
Tabel 1.

Partisipan penelitian

\begin{tabular}{|c|c|c|c|c|c|c|c|}
\hline Kode & Inisial & $\begin{array}{c}\text { Jenis } \\
\text { Kelamin }\end{array}$ & Usia & Startup & $\begin{array}{c}\text { Capaian/ Omzet } \\
\text { per tahun }\end{array}$ & $\begin{array}{l}\text { Bidang } \\
\text { Startup }\end{array}$ & $\begin{array}{c}\text { Latar } \\
\text { Pendidikan }\end{array}$ \\
\hline P1 & DRM & Laki-Laki & 25 & PS & 7000 downloaders & Healthcare & Manajemen \\
\hline $\mathbf{P 2}$ & $\mathrm{RF}$ & Laki-Laki & 23 & IW & 1,2 miliar rupiah & Agriculture & Ilmu Komputer \\
\hline P3 & FW & Laki-Laki & 29 & PS & 7000 downloaders & Healthcare & Pend. Dokter \\
\hline P4 & RA & Laki-Laki & 23 & $\mathrm{HN}$ & 600 juta rupiah & IT & IT \\
\hline P5 & HAW & Perempuan & 23 & IW & 1,2 miliar & Agriculture & Sastra \\
\hline P6 & $\mathrm{AA}$ & Laki-Laki & 22 & CS & 60 juta rupiah & Stationery & IT \\
\hline
\end{tabular}

\section{Desain penelitian}

Penelitian ini bermaksud mengungkap proses kognitif yang terjadi ketika pengusaha, khususnya founders startup digital, melakukan opportunity recognition dari perubahan teknologi yang ada. Secara sederhana, partisipan diberikan dua stimulus yang merupakan deskripsi dari dua teknologi baru. Sebelum memulai, partisipan mengisi lembar biodata dan diberikan penjelasan mengenai prosedur penelitian serta diberikan sebuah contoh praktek dari proses think aloud protocol menggunakan proses hitungan. Kemudian partisipan mengonfirmasi kejelasan prosedur penelitian serta kesediaan menjalankan prosedur penelitian termasuk merekam proses verbalisasi melalui informed consent. Setelah mengonfrimasi kesediaan, peneliti memberikan deskripsi teknologi pertama secara acak. Partisipan kemudian membaca deskripsi teknologi kemudian mendeskripsikan kemungkinan peluang kewirausahaan yang dapat diraih dengan adanya teknologi tersebut, jika ada. Partisipan dapat mengajukan pertanyaan dan menginterupsi penelitian setiap saat. Selanjutnya partisipan mengerjakan tugas kedua dengan prosedur yang sama.

\section{Metode pengolahan data}

Analisis dilakukan dengan protocol analysis dari verbalisasi partisipan saat mengidentifikasi peluang kewirausahaan. Hayes (2000) menjelaskan bahwa protocol analysis merupakan pendekatan yang secara luas digunakan dalam penelitian psikologi kognitif.

Analisis diawali dengan transkripsi melalui metode verbatim kemudian protokol masuk ke dalam proses segmentasi, yaitu proses membagi protokol ke dalam segmen tertentu dalam hal ini pernyataan sesuai jeda berhenti partisipan. Proses analisis menggunakan sebuah skema koding dari penelitian Gregoire et al., (2010). Protokol lalu diketegorisasikan sesuai dengan skema koding tersebut menggunakan perangkat lunak NVIVO 8. Kemudian peneliti menganalisis seberapa penting tiap kategori berdasarkan waktu yang digunakan partisipan dalam pernyataan tersebut dibandingkan keseluruhan total waktu. Kredibilitas data diukur dari intercoder reliability menggunakan Kappa dengan hasil 70\% korespondensi sehingga kategorisasi telah dapat diterima (Someran et al., 1994).

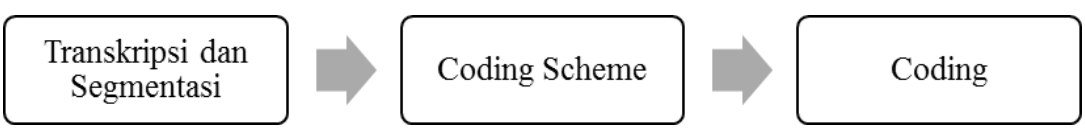

Gambar 1. Alur Analisis Data (Someran, Barnard, \& Sandberg, 1994) 
Tabel 2.

Skema koding

\begin{tabular}{|c|c|c|}
\hline $\begin{array}{l}\text { Kategori } \\
\text { Analisis }\end{array}$ & Sub-kategori & Operasionalisasi \\
\hline \multicolumn{3}{|c|}{ Attention Focus } \\
\hline \multicolumn{2}{|c|}{ Teknologi } & $\begin{array}{l}\text { ernyataan berisi komentar, observasi, pertanyaan, isu dll mengenai } \\
\text { knologi yang digunakan }\end{array}$ \\
\hline \multicolumn{2}{|l|}{ Pasar } & $\begin{array}{l}\text { ernyataan berisi komentar, observasi, pertanyaan, isu dll mengenai pasar } \\
\text { ang disampaikan }\end{array}$ \\
\hline \multirow{2}{*}{\multicolumn{2}{|c|}{$\begin{array}{l}\text { Bukan } \\
\text { keduanya }\end{array}$}} & ernyataan tidak merujuk pada teknologi maupun pasar \\
\hline & & \\
\hline $\begin{array}{l}\text { Kategori } \\
\text { Analitis }\end{array}$ & Sub-kategori & Pernyataan berisi komentar, observasi, pertanyaan, isu dll mengenai \\
\hline \multicolumn{3}{|c|}{ Level dari Structural Alignment } \\
\hline $\begin{array}{l}\text { Superficial } \\
\text { (teknologi) }\end{array}$ & $\begin{array}{l}\text { Karakteristik } \\
\text { teknologi }\end{array}$ & $\begin{array}{l}\text { Objek dari teknologi seperti bagian-bagian teknologi, elemen, material } \\
\text { atau input yang digunakan, objek atau output yang diproduksi, individu } \\
\text { yang membangun teknologi, kemunculan teknologi beserta karakteristik } \\
\text { dai objek maupun individu tersebut }\end{array}$ \\
\hline $\begin{array}{l}\text { Superficial } \\
\text { (pasar) }\end{array}$ & $\begin{array}{l}\text { Karaktersitik } \\
\text { pasar }\end{array}$ & $\begin{array}{l}\text { Objek maupun atribut /karakteristik /fitur dari konteks pasar, termasuk } \\
\text { individu pada pasar tersebut, karakteristik, produk atau layanan yang } \\
\text { mereka gunakan, karaktersitik dari produk atau layanan, karakteristik dari } \\
\text { konteks pasar secara keseluruhan }\end{array}$ \\
\hline \multirow[t]{2}{*}{$\begin{array}{l}\text { First-order } \\
\text { relationships } \\
\text { (teknologi) }\end{array}$} & $\begin{array}{l}\text { T-How: Cara } \\
\text { teknologi } \\
\text { beroperasi }\end{array}$ & $\begin{array}{l}\text { Pengoperasian teknologi, bagaimana teknologi tersebut bekerja, apa yang } \\
\text { dilakukannya, dengan apa teknologi tersebut melakukannya serta } \\
\text { bagaimana }\end{array}$ \\
\hline & $\begin{array}{l}\text { T-Why: tujuan } \\
\text { teknologi }\end{array}$ & $\begin{array}{l}\text { Tujuan awal dari teknologi pada konteks perkembangannya contohnya } \\
\text { mengapa pengembang membangun teknologi tersebut serta efek seperti } \\
\text { apa yang muncul }\end{array}$ \\
\hline \multirow[t]{2}{*}{$\begin{array}{l}\text { First-order } \\
\text { relationships } \\
\text { (market) }\end{array}$} & $\begin{array}{l}\text { M-How: } \\
\text { Bagaimana pasar } \\
\text { bekerja }\end{array}$ & $\begin{array}{l}\text { Aktivitas dalam konteks pasar tersebut seperti apa yang individu dalam } \\
\text { konteks tersebut lakukan dengan produk atau layanan yang mereka } \\
\text { gunakan saat ini, bagaiamana mereka berinteraksi dengan produk atau } \\
\text { layanan itu, bagaimana produk atau layanan tersebut berfungsi dll }\end{array}$ \\
\hline & $\begin{array}{l}\text { M-Why : tujuan } \\
\text { dari pelaku } \\
\text { pasar }\end{array}$ & $\begin{array}{l}\text { Tujuan saat ini dari individu dalam konteks pasar tersebut seperti } \\
\text { mengapa mereka melakukan apa yang mereka lakukan saat ini }\end{array}$ \\
\hline \multirow[t]{2}{*}{$\begin{array}{l}\text { High-order } \\
\text { relationships } \\
\text { (teknologi) }\end{array}$} & $\begin{array}{l}\text { T-Ben: Keun- } \\
\text { tungan dari } \\
\text { teknologi beserta } \\
\text { penyebabnya } \\
\text { (benefit) }\end{array}$ & $\begin{array}{l}\text { Potensi keuntungan/implikasi dari teknologi seperti kemampuan/efek dari } \\
\text { teknologi, serta penyebab/alasan mengapa teknologi itu memiliki } \\
\text { kemampuan tersebut }\end{array}$ \\
\hline & $\begin{array}{l}\text { T-Prob: Masalah } \\
\text { dari teknologi } \\
\text { dan } \\
\text { penyebabnya } \\
\text { (problem) }\end{array}$ & $\begin{array}{l}\text { Masalah atau keterbatasan khusus dari teknologi serta alasan/penyebab } \\
\text { dari hal tersebut }\end{array}$ \\
\hline \multirow[t]{2}{*}{$\begin{array}{l}\text { High-order } \\
\text { relationships } \\
\text { (pasar) }\end{array}$} & $\begin{array}{l}\text { M-Ben: keun- } \\
\text { tungan dari akti- } \\
\text { vitas pasar dan } \\
\text { penyebabnya }\end{array}$ & $\begin{array}{l}\text { Implikasi/keuntungan dari aksi dan aktivitas pasar seperti penggunaan } \\
\text { produk atau layanan untuk tujuan tertentu }\end{array}$ \\
\hline & $\begin{array}{l}\text { M-Prob: masalah } \\
\text { dari pasar dan } \\
\text { penyebabnya }\end{array}$ & $\begin{array}{l}\text { Masalah yang dimiliki individu dalam konteks pasar, keterbatasan dari } \\
\text { aktivitas maupun produk/layanan yang mereka gunakan di pasar, } \\
\text { termasuk tujuan, motif dan kebutuhan dari individu yang belum } \\
\text { terpuasakan pada kondisi saat ini, atau alasan mengapa masalah dan } \\
\text { keterbatasan ini ada }\end{array}$ \\
\hline
\end{tabular}




\begin{tabular}{|c|c|c|}
\hline $\begin{array}{l}\text { Implicit } \\
\text { (teknologi), } \\
\text { Implicit } \\
\text { (pasar) }\end{array}$ & & $\begin{array}{l}\text { Meskipun pernyataan mendiskusikan hal ini, akan tetapi pernyataan } \\
\text { tersebut secara implisit merujuk pada sesuatu pada konteks pasar atau } \\
\text { teknologi. Karena pernyataan secara implisit sehingga tidak mungkin } \\
\text { mengkategorikan pernyataan pada level dari structural alignment yang } \\
\text { digunakan. }\end{array}$ \\
\hline $\begin{array}{l}\text { Kategori } \\
\text { Analisis } \\
\end{array}$ & Sub-kategori & Operasionalisasi \\
\hline \multicolumn{3}{|c|}{ Proses mendasarkan reasoning pada level prior knowledge tertentu } \\
\hline Rendah & $\begin{array}{l}\text { Pengetahuan } \\
\text { minimum }\end{array}$ & $\begin{array}{l}\text { Pernyataan tidak secara eksplisit atau implisit didasarkan pada domain } \\
\text { pengetahuan khusus yang diklaim individu }\end{array}$ \\
\hline \multirow[t]{2}{*}{ Medium } & $\begin{array}{l}\text { Wawasan } \\
\text { Umum }\end{array}$ & $\begin{array}{l}\text { Pernyataan merujuk pada sebuah domain pengetahuan yang diklaim } \\
\text { individu merupakan hal yang cukup familiar, mengetahui sesautu tanpa } \\
\text { menjadi ahli atau secara langsung tertarik pada domain tersebut } \\
\text { contohnya adalah domain yang belum pernah dialami secara langsung } \\
\text { oleh individu itu sendiri }\end{array}$ \\
\hline & $\begin{array}{l}\text { Pengetahuan } \\
\text { terbatas }\end{array}$ & $\begin{array}{l}\text { Pernyataan merujuk pada domain pengetahuan yang secara eksplisit } \\
\text { merupakan pengetahuan terbatas seperti memori masa lalu, kejadian } \\
\text { terdahulu, kejadian yang tidak signifikan secara khusus atau membang- } \\
\text { kitkan emosi individu }\end{array}$ \\
\hline \multirow[t]{4}{*}{ Tinggi } & $\begin{array}{l}\text { Pengalaman } \\
\text { pribadi }\end{array}$ & $\begin{array}{l}\text { Pernyataan merujuk pada domain pengetahuan yang secara eksplisit dan } \\
\text { langsung berkaitan dengan sebuah pengalaman pribadi yang sangat } \\
\text { ditandai, pengalaman pribadi yang bermakna dan penting. }\end{array}$ \\
\hline & $\begin{array}{l}\text { Pengalaman } \\
\text { keluarga }\end{array}$ & $\begin{array}{l}\text { Pernyatan merujuk pada domain pengetahuan yang secara eksplisit dan } \\
\text { langsung berkaitan dengan anggota kelaurga seperti pasangan, anak, } \\
\text { orang tua dll }\end{array}$ \\
\hline & $\begin{array}{l}\text { Ketertarikan } \\
\text { personal }\end{array}$ & $\begin{array}{l}\text { Pernyataan merujuk pada domain pengetahuan yang diklaim oleh } \\
\text { individu memiliki ketertarikan personal seperti hobi }\end{array}$ \\
\hline & $\begin{array}{l}\text { Keahlian } \\
\text { profesional }\end{array}$ & $\begin{array}{l}\text { Pernyataan merujuk pada domain pengetahuan yang berkorespondensi } \\
\text { kepada bidang individu atau keahlian profesionalnya }\end{array}$ \\
\hline
\end{tabular}

\section{Hasil}

Temuan pertama dari kategorisasi attention focus ditemukan bahwa partisipan menghabiskan lebih banyak waktu untuk mendiskusikan pasar (demand) daripada teknologi yang disajikan (supply). Temuan kedua, menariknya secara spontan atau tanpa instruksi, proporsi terbesar dari verbalisasi partisipan saat melakukan opportunity recognition difokuskan pada teknologi dan pasar sekaligus (pasarteknologi), yaitu pernyataan-pernyataan yang maknanya mengandung hubunganhubungan antara teknologi yang disajikan dan pasar untuk mangaplikasikan teknologi tersebut sebesar 39,21\%. Hal ini dapat dilihat pada Gambar 2 serta berikut contoh pernyataan partisipan.
"Bisa jadi bikin game yang apa, memang didesain untuk melatih konsentrasinya dia, dia kan ngga bisa diem biasanya yang anak-anak yang kaya gitu itu lho, ada aja, kalau suruh konsentrasi suruh diem kan ngga bisa. Jadi efeknya setelahnya, jadi efeknya ngga cuma pas dia main game tapi juga bisa setelahnya." (P2_RF_IW_SMART/Ref2/Keduanya).

Selanjutnya pada temuan ketiga dapat dilihat bahwa pengusaha lebih menggunakan proses structural relationship dibandingkan dengan superficial features dari hasil analisis keduabelas protokol. Pengusaha menggunakan proses reasoning superficial features hanya secara moderat dengan rata-rata cakupan sebesar 5,83\% 


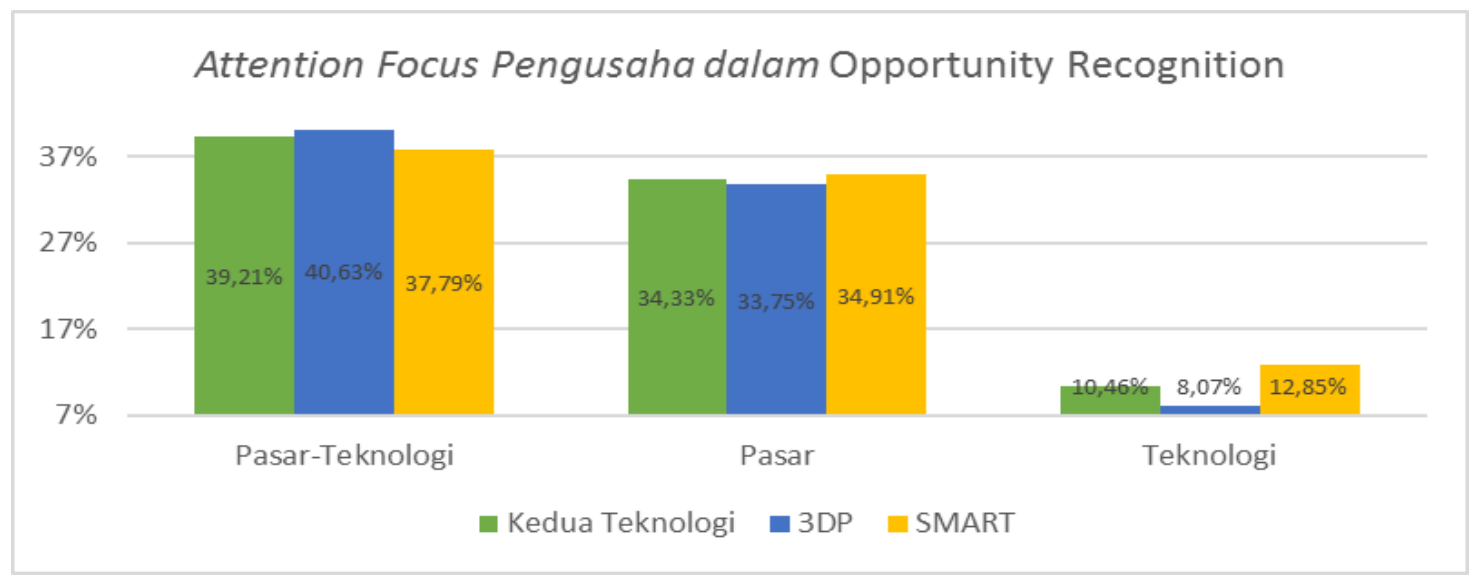

Gambar 2. Attention Focus Pengusaha dalam Opportunity Recognition

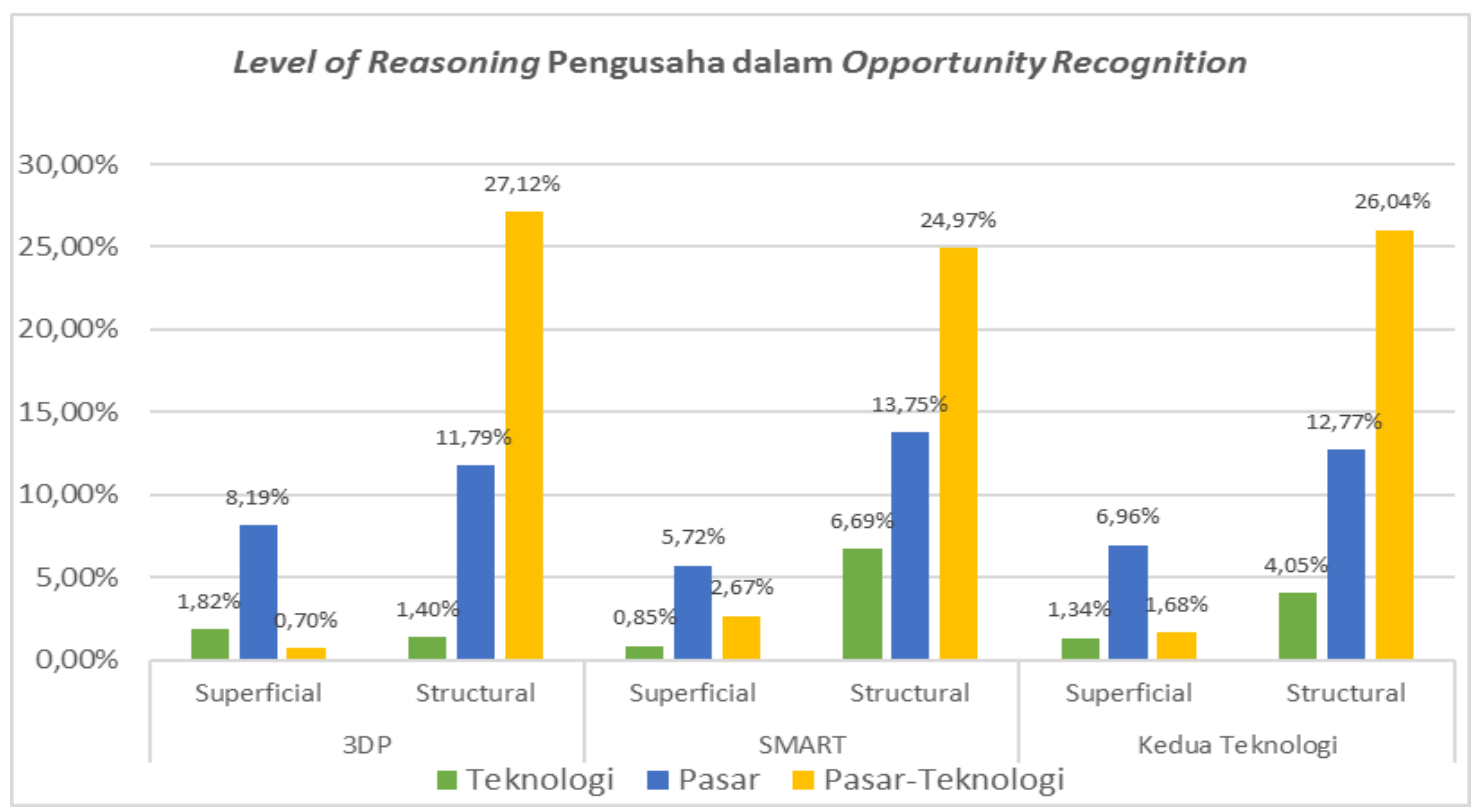

Gambar 3. Level of Reasoning Pengusaha dalam Opportunity Recognition

dari keseluruhan waktu protokol. Superficial features digunakan ketika partisipan cenderung memberikan deskripsi pada suatu hal tanpa adanya abstraksi maupun pengolahan informasi lebih lanjut melalui hubungan-hubungan tertentu. Disisi lain, structural relationship merupakan pemrosesan informasi yang lebih kompleks dengan membuat perbandingan antar bagian-bagian informasi menjadi hubungan-hubungan tertentu. Dari data yang diperoleh, rata-rata pengusaha menggunakan $28,15 \%$ structural relationship dari keseluruhan waktu.
Dalam menggunakan proses reasoning structural relationship pengusaha menggunakan dua jenis hubungan yaitu first order dan higher order relationship. Secara umum pengusaha cenderung lebih menggunakan higher order relationship dibandingkan first order relationship dari keseluruhan waktu protokol.

First order relationship menunjukkan pemrosesan informasi baru dengan membandingkan secara langsung bagianbagian informasi tersebut maupun dengan informasi yang telah individu miliki sebelumnya. Melalui analisis lebih dalam penelitian ini menemukan bahwa dalam 
proses reasoning first order relationship partisipan berfokus pada proses pasar beroperasi, aktivitas maupun produk yang ada di pasar (M-How) yaitu sebesar 15,86\% dari keseluruhan protokol.

"Itu yang buat, uhm CNC itu buat anak mesin biasanya dia kaya, kaya punya buat ngukir atau apa, bentuk kaya laser gitu lho. Nanti bisa mbentuk apa gitu lho, sesuai yang nanti ya mau bentuk apa, kita udah desain nanti dia kaya ngeleser gitu. Kalau printer 3D ini kan bisa detail. Nah kalau sekarang itu adanya CNC uhmm" (P2_RF_IW_3DP/Ref5/M-How)

Di sisi lain, higher order relationship menunjukkan abstraksi hubungan yang lebih kompleks dibandingkan first order relationship. Melalui penelitian ini dapat diketahui bahwa pengusaha cenderung lebih memberikan perhatian mereka pada masalah, keterbatasan maupun kebutuhan yang belum terpenuhi dari pasar yang mereka deskripsikan (M-Prob) serta pada kelebihan, manfaat maupun implikasi dari adanya teknologi yang diberikan dalam penelitian ini (T-Ben). Dalam mendeskripsikan masalah pasar (M-Prob) rata-rata partisipan menghabiskan 35,40\% dari keseluruhan total waktu protokol serta mendiskusikan manfaat teknologi (T-Ben) rata-rata sebesar $41,51 \%$ dari verbalisasi partisipan. Berikut merupakan contoh pernyataan partisipan baik dari T-Ben dan M-Prob.

“Dan skalabilitas yang aku lihat, dan kemampuan kapitalisnya uhm apa eee kebutuhan kapitalnya itu ngga terlalu tinggi, dimana eee yang dulu kita mau bikin sesuatu, akhirnya kita harus ke pabrik besar, dengan skala yang besar, ya high cost lah, high cost, high capital gitu lho, sekarang dengan adanya 3D printing ini ya, semuanya kan serba individual ya, custom, di mana, setiap orang yang punya dana, dana yang ngga terlalu besar pun dia bisa, ngeprint secara 3D gitu lho"(P1_DRM_3DP/Ref2/T-Ben)

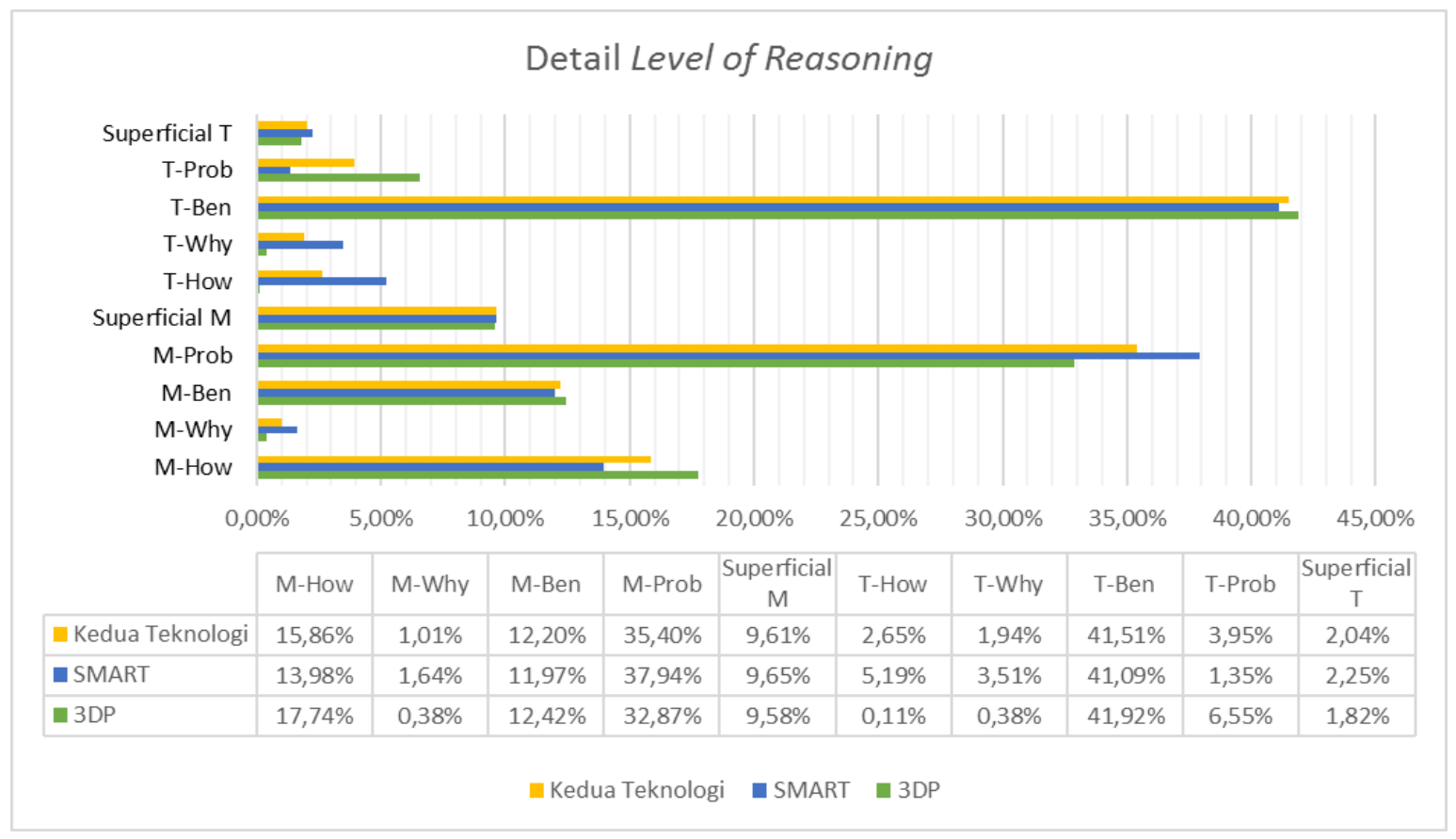

Gambar 4. Detail Level of Reasoning 
"karena kadang-kadang kan, eee seorang pembuat game itu kan, menebak menurut kemampuan dia gitu lho, melalui UI UX nya dan lainlain gitu lho, jadi kesulitannya adalah, bagaimana menebak si eee market ini sesuai kebutuhan atau engga sih, apakah ini terlalu susah atau terlalu mudah karena kan kalau terlalu mudah bakalan ditinggal dan kalau terlalu susah ngga ada yang main jadinya dengan analisis smart ini kita bisa kita bisa mendeteksi masa depan, forecast-nya itu oke ketika itu," (P1_DRM_SMART/Ref3/M-Prob)

Temuan tersebut didukung melalui analisis dari proses reasoning ketika pengusaha memberikan fokus mereka pada teknologi-pasar sekaligus. Ketika pengusaha memfokuskan perhatian mereka pada kedua sisi supply dan demand, partisipan cenderung lebih mengolah in formasi mengenai M-Prob atau masalahmasalah dan keterbatasan yang dialami oleh pasar yaitu sebesar 26,37\% dari keseluruhan protokol serta kelebihan yang mampu diberikan oleh teknologi atau TBen yaitu sebesar 38,52\%.

Disisi lain ketika sedang memberikan perhatian pada teknologi saja maupun pasar saja, partisipan cenderung lebih mengolah kelebihan dari sisi-sisi tersebut.
Dari analisis yang dilakukan ditemukan bahwa ketika pengusaha memberikan fokus mereka pada teknologi (supply) saja, pengusaha lebih mengolah informasi mengenai manfaat yang dapat diperoleh dari teknologi tersebut atau T-Ben. Pada sisi pasar saja, partisipan cenderung mengolah kelebihan dari aktivitas di pasar tersebut untuk menemukan peluang yang dianggap sesuai atau M-Ben.

Penelitian ini juga menganalisis prior knowledge yang digunakan oleh pengusaha dalam proses opportunity recognition. Dari analisis yang dilakukan dapat dipahami bahwa proses identifikasi peluang yang dilakukan partisipan melibatkan prior knowledge medium hingga tinggi dengan rata-rata penggunaan prior knowledge tinggi mencakup 31,27\% dari keseluruhan waktu protokol, serta prior knowledge medium mencakup 36,06\% dari keseluruhan waktu protokol.

Analisis lebih dalam pada kategori medium dan tinggi menunjukkan bahwa pengusaha cenderung menggunakan pengetahuan umum mereka serta pengalaman pribadi dalam memformulasikan peluang kewirausahaan. Wawasan umum yang digolongkan sebagai level of prior knowledge medium rata-rata mencakup $41 \%$ dari keseluruhan protokol serta pengalaman pribadi yang digolongkan sebagai level of prior knowledge tinggi mencakup 25,7\%, hal ini secara rinci dapat dilihat pada Gambar 6 .

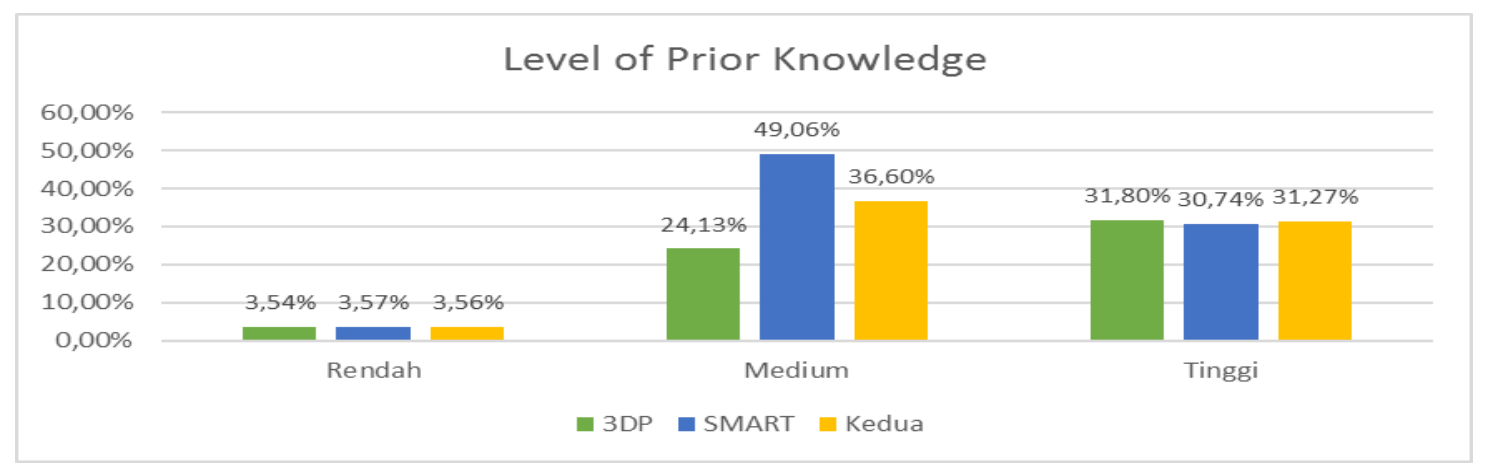


Gambar 5. Level of Prior Knowledge

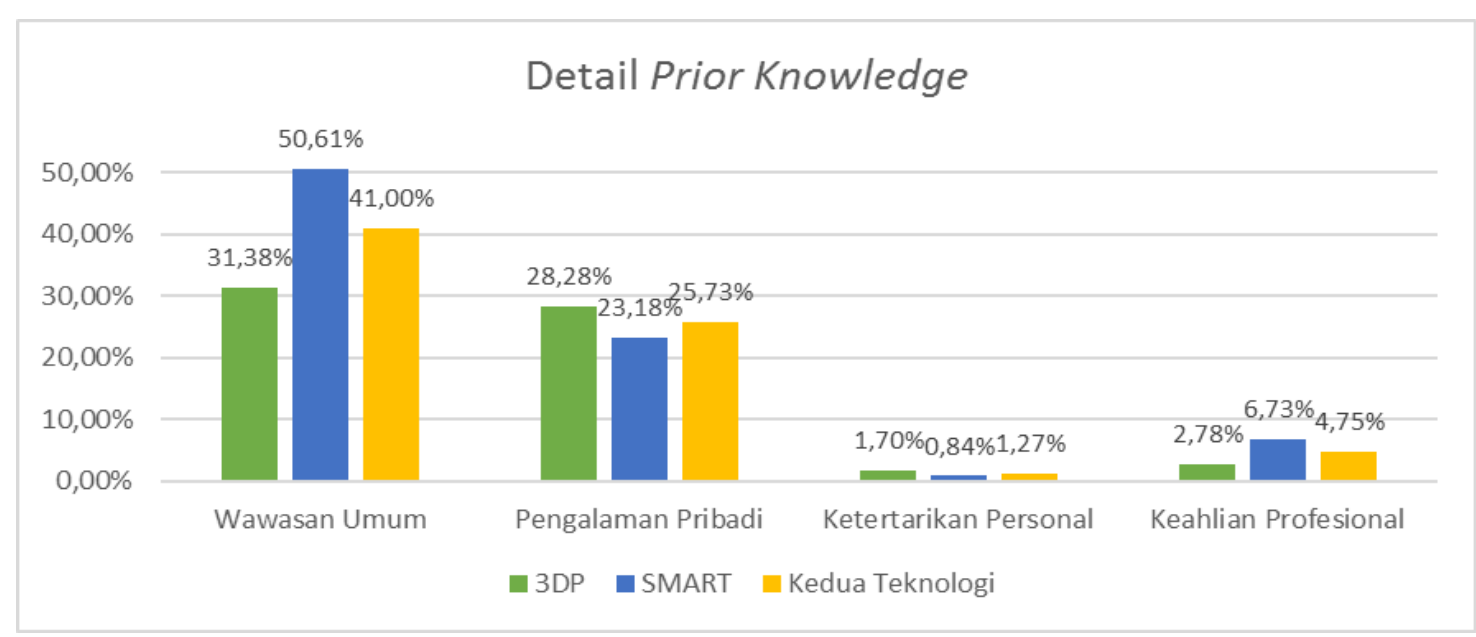

Gambar 6. Detail Prior Knowledge

Analisis prior knowledge juga dilakukan kepada isi konten verbalisasi partisipan yaitu hasil peluang usaha yang dirumuskan. Peluang usaha yang diutarakan partisipan selama proses think aloud protocol kemudian dianalisis berdasarkan latar belakang pendidikan partisipan serta bidang usaha dari startup masing-masing partisipan.

Dari analisis yang dilakukan, usaha yang diciptakan partisipan dalam penelitian ini selaras dengan latar belakang partisipan. Meskipun partisipan menciptakan beberap peluang kewirausahaan sekaligus selama proses think aloud protocol, akan tetapi tetap ada satu peluang yang selaras dengan latar belakang mayoritas partisipan yang menunjukkan peran prior knowledge dalam proses opportunity recognition.

Sebagai contoh dalam merekognisi peluang mengenai 3DPTM, partisipan 1 DRM yang menggeluti bidang healthcare merumuskan peluang untuk membuat alat kesehatan khusus menggunakan 3DPTM demi menyediakan alat yang selama ini sulit didapat di daerah rural area. Begitu juga pada partisipan 3 FW yang memiliki latar belakang pendidikan yaitu pendidikan dokter dan menggeluti startup dibidang healthcare. Peluang-peluang kewirausahaan yang diciptakan partisipan $3 \mathrm{FW}$ berkisar mengenai industri kesehatan dan berbagai masalah yang ada dalam industri keseahatan terkini. Partisipan FW juga membuat sebuah peluang yang mengintegrasikan bisnis yang digeluti saat ini yaitu PS dengan teknologi SMART ${ }^{\mathrm{TM}}$ yang disajikan.

"Ide lain ide lain pastinya ini sih, eee akan eee akan berkembang terus sih, tapi akhire ya misale di sektor kesehatan sendiri nih misalnya di PS aku kan punya PS. Di sektor kesehatan pun nantinya orang akan order sesuatu secara misalnya nyetak nyetak sesuatu tools tools kesehatan pun yang sekarang pabrik gitu lho, dengan adanya kan bisa juga custom gitu lho. Custom di mana misale aku belum tau detailnya tapi ya intinya eee sesuai sama apa yang dibutuhin sama perusahaan tapi ngga terlalu tinggi pembiayaannya ngga terlalu tinggi pembiayaan apa order-nya gitu lho di mana mesinnya 3D, di mana bisa dimanfaatin di rural area misalnya di 
kaya semua persebaran ee misalnya tenaga kesehatan di Indonesia kan eee hanya berfokus di Jawa mungkin ya. Jadi semua alat-alat hebat itu ada disini gitu lho tapi dengan adanya ini yang di mana hardware-nya bukan yang technology based ya. Hardware-nya misalnya alat-alat apa itu bisa dicetak gitu lho."

Analisis dari masing-masing individu tersebut memperkuat gagasan bahwa simpanan pengetahuan partisipan atau prior knowledge sangat memengaruhi proses opportunity recognition yang mereka lakukan. Pengetahuan individu yang bervariasi menjadikan munculnya beragam peluang kewirausahaan yang berbeda meskipun dihadapkan pada perubahan teknologi yang sama. Prior knowledge individu inilah yang menjadi poin penting yang membedakan satu individu dengan individu lain.

\section{Diskusi}

Hasil penelitian ini menunjukkan bahwa pengusaha startup digital memfokuskan perhatian atau cognitive effort pada pasar (demand) dan (supply) sekaligus yaitu pernyataan yang membangun hubungan pada kedua aspek tersebut. Pengusaha lebih menggunakan penalaran structural alignment yang berarti bahwa pengusaha membangun hubungan, baik hubungan sebab akibat maupun kondisional. Hubungan tersebut khususnya pada kelebihan atau implikasi dari teknologi (supply) untuk menyelesaikan masalah dari pasar (demand).

Baron (2006) menyatakan bahwa pada proses opportunity recognition, pengusaha mengidentifikasi pola tertentu untuk menghubungkan dan memahami berbagai informasi. Setiap hari individu menemui beragam informasi baru, dalam mengolah informasi ini individu menggunakan cognitive framework yang telah mereka miliki untuk menemukan hubungan dari informasi baru tersebut. Individu tertentu mengidentifikasi peluang kewirausahaan karena mereka mempersepsi hubunganhubungan antara kejadian-kejadian yang terlihat independen seperti perkembangan teknologi dan permasalahan pasar kemudian mendeteksi pola-pola bermakna (meaningful pattern) atau pola yang mengarahkan pada sebuah peluang kewirausahaan baru.

Hal tersebut dapat dijelaskan melalui teori pattern recognition yang mengungkap proses ketika individu mengidentifikasi pola-pola yang bermakna dari kompleksitas berbagai kejadian yang ditemui sehari-hari. Proses kognitif menggunakan pattern recognition melibatkan proses bottom-up processing serta top-down processing sekaligus. Bottom-up processing menekankan pada pentingnya informasi dari stimulus yang masuk ke dalam proses kognitif individu, sebaliknya, top-down processing menekankan pada pengaruh dari konsep, harapan dan memori yang digunakan dalam pemrosesan kognitif. Proses pattern recognition mengintegrasikan kedua pemrosesan tersebut secara bersamaan melalui pemrosesan stimulus yang ditemui yang dihubungkan dengan konsep dan memori yang telah dimiliki. Proses pattern recognition ini membantu individu untuk memahami hubunganhubungan kompleks dari stimulus (Matlin, 2008).

Baron (2006) menyebutkan bahwa individu mampu untuk menghubungkan titik-titik atau "connect the dots" pada kejadian dan perubahan yang mereka proses. Dalam penelitian ini partisipan penelitian cenderung mampu memfokuskan cognitive effort mereka terhadap pasar dan teknologi sekaligus serta 
menghubungkan titik-titik yang ada pada keduanya melalui pemrosesan structural alignment. Dari penelitian ini juga ditemukan bahwa titik-titik yang dikorelasikan pengusaha yaitu kelebihan maupun implikasi yang bisa diciptakan dari sisi supply atau teknologi untuk menyelesaikan masalah ataupun keterbatasan yang dimiliki pasar atau sisi demand. Dalam proses opportunity recognition, pengusaha bukan hanya mampu mendeskripsikan informasi baru yang mereka temui, namun juga mampu mengolah bagian-bagian dari deskripsi informasi tersebut yang terlihat independen menjadi pola bermakna melalui pemrosesan high-order relationship pada structural relationship. Melalui pemrosesan kognitif tersebut individu mampu mengidentifikasi peluang kewirausahaan.

Ditambah lagi, penelitian ini menunjukkan peran prior knowledge dalam opportunity recognition. Pengetahuan dan pengalaman menjadi sebuah prototype yang memberikan panduan bagi individu untuk mengolah informasi dari kejadian yang mereka temui. Hal ini lah yang membedakan satu individu dengan individu lain, di antara mereka ada yang memiliki prototype tertentu yang membuat mereka menyadari adanya sebuah peluang bisnis dari perubahan-perbahan yang terjadi. Prior knowledge atau pengetahuan sebelumnya ini terakumulasi menjadi sebuah prototype yang berperan sebagai cognitive framework yang dimiliki individu dalam mempersepsi peluang kewirausahaan. Temuan ini memberikan penjelasan mengapa terdapat individu yang berhasil mempersepsi peluang serta terdapat individu yang tidak.

Peran prior knowledge ini juga memberikan sanggahan kepada pandangan ekonomi neoklasikal yang berasumsi bahwa orang-orang akan menemukan peluang yang sama ketika dihadapkan pada perubahan teknologi (Khilstrom \& Laffont, 1979). Pasar berada pada keadaan equilibrium karena semua individu rasional dan informasi terdistribusi sempurna sehingga semua orang dapat mengidentifikasi peluang kewirausahaan serta atribut dasar individu, bukan informasi yang mereka miliki yang menentukan sosok yang menjadi pengusaha.

Bertentangan dengan pandangan tersebut, Austrian School of Economics berpandangan bahwa masing-masing individu akan menemukan peluang yang berbeda dari adanya perubahan teknologi karena mereka memproses simpanan pengetahuan (prior knowledge) yang berbeda serta informasi tentang peluang lebih menentukan sosok yang menjadi pengusaha daripada atribut dasar individu. Meskipun informasi mengenai sebuah perubahan teknologi dipublikasikan luas kepada publik, tetapi tidak semua individu memiliki simpanan informasi yang dapat memantik identifikasi peluang kewirausahaan baru dari adanya perubahan tersebut (Shane, 2000).

Meskipun prior knowledge memiliki peran penting dalam proses opportunity recognition, perlu dipahami bahwa simpanan pengetahuan tersebut bukan berperan selayaknya exemplar model, sebuah model khusus dari pattern recognition. Exemplar models menyatakan bahwa individu yang menemui sebuah kejadian atau stimulus baru akan membandingkan stimulus tersebut dengan contoh spesifik (exemplars) dari konsep relevan yang tersimpan di memori individu (Hahn \& Chater, 1997). Baron (2006) menyatakan bahwa pengusaha menggunakan exemplars mereka untuk secara sederhana membandingkan kejadian baru yang mereka temui dengan contoh yang sama dari konsep yang telah tersimpan dalam memori. Akan tetapi 
penelitian ini menemukan bukti pada pandangan yang berbeda. Pengusaha tidak serta merta mencocokan pasar dan teknologi tetapi mengolah titik informasi seperti masalah yang dihadapi pasar dan kelebihan teknologi menjadi sebuah peluang kewirausahaan baru. Sebagai tambahan, penelitian ini juga mengungkap integrasi dari proses identifikasi peluang secara allocative, discovery dan creation. Terdapat perdebatan panjang mengenai sifat ontologis peluang. Merunut pada pandangan Schumpeter (dalam George, et al. 2016) peluang adalah suatu hal yang ditemukan, sedangkan Kirzner (dalam George et al. 2016) menyatakan bahwa elemen dari rekognisi (allocative) individu terlibat dalam mendeteksi peluang serta Drucker (1985) menyatakan bahwa peluang adalah bagian dari proses penciptaan (creation). Selaras dengan pandangan Sarasvathy, Dew, Velamuri, \& Venkataraman (2003), peluang merupakan sebuah fenomena yang memuat proses allocative, discovery sekaligus creation. Dalam penelitian ini, partisipan menciptakan sebuah inovasi dari adanya teknologi terbaru yang merupakan perwujudan dari proses creation, mengolah informasi dalam penemuan pasar yang tepat atau proses discovery, serta mengidentifikasi titik-titik informasi tersebut menjadi sebuah peluang kewirausahaan melalui representasi mental individu yang merupakan manifestasi proses allocative atau rekognisi. Proses tersebut tidak secara spesifik menjadikan identifikasi peluang sebagai salah satu dari pandangan allocative, discovery maupun creation, tetapi justru merupakan fenomena yang terwujud dari integrasi ketiga pandangan tersebut.

Dari hasil dan analisis penelitian maka dapat disimpulkan model opportunity recognition pada pengusaha khususnya founder startup digital. Penelitian ini menunjukkan dalam proses identifikasi peluang kewirausahaan dibutuhkan dua aspek dari seorang individu yaitu memiliki prior knowledge atau simpanan pengetahuan dan informasi serta pemrosesan kognitif untuk mengeolah informasi tersebut. Selain itu dibutuhkan adanya perubahan khusus yang memantik munculnya informasi baru atau ketidakseimbangan informasi sehingga individu menyadari adanya potensi peluang.

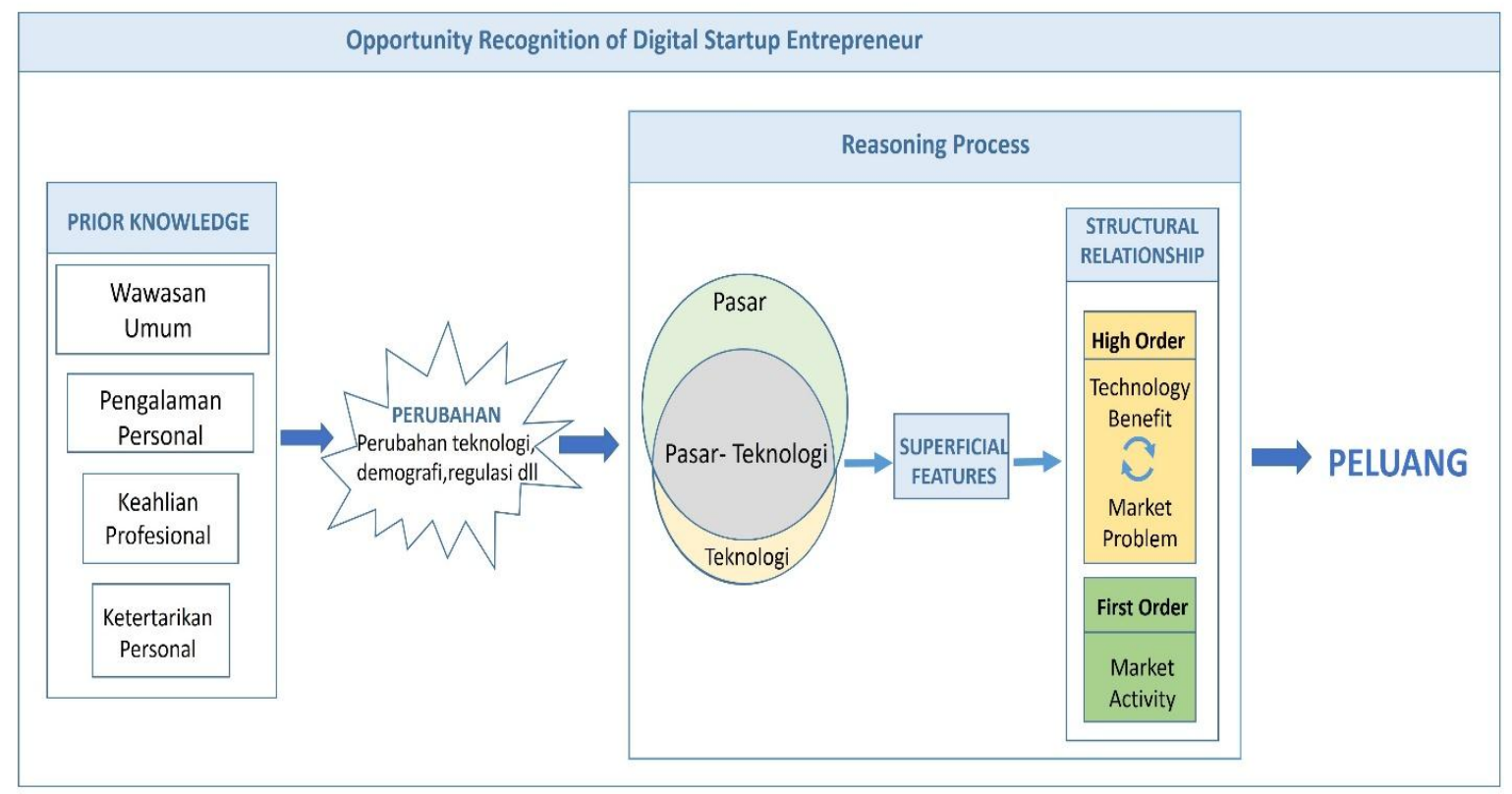




\section{Gambar 7. Model Opportunity Recognition pada Pengusaha Startup Digital}

Secara umum dapat disimpulkan bahwa hasil penelitian ini selaras dengan pandangan Gregoire et al., (2010) mengenai peran proses structural alignment dalam opportunity recognition yang menjadi rujukan utama penelitian ini. Akan tetapi temuan penelitian ini menunjukkan proses kognitif structural alignment bukan hanya ditemukan pada executive entrepreneur tetapi juga pada pengusaha level startup khususnya startup digital sehingga mempertegas generalisasi dari pandangan ini.

\section{Kesimpulan}

Dari model yang dirumuskan dalam penelitian ini terangkum bahwa pengusaha memiliki prior knowledge yang berasal dari pengetahuan familiar, pengalaman personal, keahlian professional maupun ketertarikan personal. Individu menyadari adanya perubahan kemudian menggunakan prior knowledge tersebut untuk melakukan proses pengolahan informasi atau proses reasoning. Dalam pengolahan informasi tersebut individu memfokuskan perhatian terbesarnya atau cognitive effort pada pasar-teknologi sekaligus. Individu menggunakan superficial features untuk mendeskripsikan informasi yang ditemui dan memahami karakteristik atau fitur dari informasi tersebut. Individu memproses informasi tersebut secara lebih dalam melalui pemrosesan structural relationship yaitu dengan membangun hubunganhubungan dari informasi yang ada. Pada pemrosesan structural relationship pengusaha lebih menggunakan high order relationship yang membangun hubungan kausalitas, hubungan kondisional atau pernyataan tujuan sedangkan dari first order relationship hanya membandingkan satu lawan satu. Bagian informasi yang dihubungkan melalui high order relationship khususnya pada manfaat atau implikasi dari teknologi demi menyelesaikan permasalahan yang ada di pasar. Model ini sekaligus menjawab pertanyaan mendasar kewirausahaan mengenai apakah individu dapat dilatih agar dapat merekognisi peluang. Individu dapat mengikuti model yang disusun dari penelitian ini serta memperkuat simpanan pengetahuan yang dimiliki sehingga dapat berperan sebagai cognitive framework yang memandu pengolahan informasi. Penelitian ini juga memberikan sebuah pemahaman baru pada proses berpikir pengusaha pemula startup digital yang masih kurang digali selama ini serta menjawab pertanyaanpertanyaan dasar kewirausahaan.

\section{Saran}

Salah satu pertanyaan mendasar mengenai keiwirausahaan serta menjadi salah satu aspek penting bagi pendidikan kewirausahaan adalah, dapatkah individu dilatih agar dapat menjadi lebih mampu merekognisi peluang? Melalui pattern recognition (Baron, 2006) serta hasil penelitian ini, terdapat beberapa implikasi yang dapat ditarik. Berdasar penelitian ini, pengusaha merupakan sosok yang mampu menghubungkan bagian-bagian informasi dari perubahan yang terjadi.

Pertama, individu dapat lebih memfokuskan usaha mereka dalam mengidentifikasi perubahan yang terjadi. Perubahan ini dapat berupa perubahan teknologi, demografis, pasar maupun faktor-faktor lain yang memiliki peran penting dalam suksesnya sebuah bisnis (Shane, 2003). Kedua, ketika individu terlibat secara aktif dalam mengolah informasi mengenai perubahan tersebut, individu dapat memfokuskan pada hubungan-hubungan yang muncul pada sisi supply dan demand. Individu dapat mencoba memahami polapola bermakna dari informasi yang diolah. 
Melalui pemrosesan struktural alignment, individu dapat mengamati aspek-aspek yang ada pada informasi tersebut, kemudian mencoba mencari hubungan dari aspek-aspek yang ada. Dari penelitian ini diketahui bahwa pengusaha mengolah informasi mengenai masalah-masalah yang ada di pasar serta kelebihan yang dapat diberikan dari sisi supply. Dengan memfokuskan cognitive effort individu pada hal tersebut, individu dapat berlatih melihat peluang yang mungkin muncul. Gregoire et al., (2010) menyebutkan bahwa pemrosesan superficial features dapat mengawali pengolahan informasi tersebut. Secara spesifik, individu dapat memulai dengan mendeskripsikan aspek-aspek dari informasi yang mereka terima, kemudian mulai mencari hubungan-hubungan seperti hubungan sebab-akibat, kondisional maupun mengolah tujuan.

Ketiga, melalui temuan mengenai prior knowledge serta teori pattern recognition (Baron, 2006), individu dapat memperluas wawasan dan pengalaman untuk meningkatkan simpanan informasi yang mereka miliki. Penelitian ini menemukan bahwa pengusaha menggunakan simpanan pengatahuan mereka dalam mengolah informasi baru yang mereka temui.

\section{Kepustakaan}

Acs, Z., \& Audretsch, D. (2005). Handbook of entrepreneurship research: An interdisciplinary survey and introduction. New York: Springer Science+Bussines Media, Inc.

Amalia, E. I. (2016, Juni 12). Di Asia Tenggara, Indonesia punya startup paling banyak. Diunduh Oktober 25, 2016, dari MetroTvNews.com:

http://teknologi.metrotvnews.com/ne ws-teknologi/9K5G0Dlb-di-asia- tenggara-indonesia-punya-startuppaling-banyak

Baron, R. (1998). Cognitive mechanisms entreprenuership: Why and when entrepreneurs think differently than other people. Journal of Business Venturing, 13(4), 275- 294.

Baron, R. (2004). The cognitive perspective: A valuable tool for answering entrepreneurship's basic "why" questions. Journal of Business Venturing, 19(2), 221-239. doi: 10.1016/S0883-9026 (03)00008-9

Baron, R. (2006). Opportunity recognition as pattern recognition: How entrepreneurs "connect the dots" to identify new business oportunities. Academy of Management Perspectives, 20(1), 104 119. doi: $10.5465 / a m p .2006 .19873412$

Buchari, A. (2009). Manajemen pemasaran dan pemasaran jasa. Bandung: Alfabeta.

Busenitz, L., \& Barney, J. (1997). Differences between entrepreneurs and managers in large organizations: Biases and heuristics in strategic decision-making. Journal of Business Venturing, 12(1), 9-30. doi: 10.1016/ S0883-9026(96)00003-1

Dahl, D. W., \& Moreau, C. P. (2002). The influence and value of analogical thinking during new product ideation. Journal Marketing Res, 39(1), 47-60. doi: 10.1509/jmkr.39.1.47.18930

Drucker, P. (1985). Innovation and entrepreneurship. New York: Harper \& Row.

Dunbar, K. (1993). Concept discovery in a scientific domain. Cognitive Science, 17(3), 397-434. doi: 10.1207/ s15516709cog1703_3

Gaglio, C. M., \& Katz, J. (2001). The psychological basis of opportunity identification: Entrepreneurial alertness. Small Business Economics, 16(2), 95-111. 
Gartner, W. (1989). "Who is an Entrepreneur?" is the wrong question. Entrepreneurship Theory and Practice, 14(1), 47-66.

Geldhof, G., Malin, H., Johnson, S., Porter, T., Bronk, K., Weiner, M., . . Damon, W. (2014). Entrepreneurship In young adults: Initial findings from the young entreprenuers study. Journal of Development Psychology, 35(5), 410- 421. doi: 10.1016/j.appdev.2014.07.003

Gentner, D. (1983). Structure-mapping: A theoretical framework for analogy. Cognitive Science, 7(2), 155-170.

Gentner, D. (1989). The mechanisms of analogical learning. In S. Vosniadou, \& A. Ortony, Similarity and analogical reasoning (pp. 199-241). Cambridge: Cambridge University Press.

Gentner, D., Rattermann, M. J., \& Forbus, K. D. (1993). The roles of similarity in transfer: Separating retrievability from inferential soundness. Cognitive Pscyhology, 25(4), 524-575.

Gentner, D., Rattermann, M. J., Markman, A. B., \& Kotovsky, L. (1995). Two forces in the development of relational similarity. In T. J. Simon, \& G. S. Halford, Developing cognitive competence: New approaches to process modeling (pp. 263-313). Hilsdale, NJ: Lawrence Erlbaum Associates.

George, N., Parida, V., Lahti, T., \& Wincent, J. (2016). A systematic literature review of entrepreneurial opportunity recognition: Insights on influencing factors. International Entreprenurship Management Journal, 309-350. doi:10.1007/s11365-014-0347-y

Gregoire, D., Barr, P., \& Shepherd, D. (2010). Cognitive processes of oppportunity recognition: The role of structural alignment. Organization Science,
21(2), 413-431. doi: 10.1287/orsc. 1090.0462

Hahn, U., \& Chater, N. (1997). Concepts and similarity. In K. Lamberts, \& D. Shanks, Knowledge, concepts, and categories (pp. 43-92). Cambridge: MIT: Press.

Hayes, N. (2000). Doing psychological research. Buckingham: Open University Press.

Holland, J., Holyoak, K. J., Nisbett, R. E., \& Thagard, P. (1986). Induction: Processes of inference, learning, and discovery. Bradford: MIT Press Cambridge.

Holyoak, K. J. (1985). The pragmatics of analogical transfer. In G. H. Bower, The psychology of learning and motivation (pp. 59-87). New York: Academic Press.

Khilstrom, R., \& Laffont, J. (1979). A general equilibrium entrepreneurial theory of firm formation based on risk aversion. Journal of Politic and Economy, 87(4), 719748.

Kominfo.go.id. (2016, Juni 17). Kominfo luncurkan gerakan nasional 1000 startup digital. Diunduh Oktober 26, 2016, dari Kominfo.go.id:

https://www.kominfo.go.id/content/de tail/7689/kemkominfo-bersama-kibarluncurkan-gerakan-nasional-1000startup-digital/0/berita_satker

Krueger, N. (2003). The cognitive psychology of entrepreneurship. In Z. Acs, \& D. Audretsch, Handbook of entreprenurship research (pp. 105 - 140). Great Britain: Kluwer Academic Publisher.

Matlin, M. W. (2008). Cognition. New Jersey: John Wiley \& Sons.

Pradana, R. S. (2013, Februari 04). Wirausaha: Indonesia butuh 4,8 juta pengusaha pemula. Diunduh Oktober 2016, dari Bisnis.com: 
http://entrepreneur.bisnis.com/read/20 130204/88/134728/wirausahaindonesia-butuh-4-8-juta-pengusahapemula

Ryza, P. (2016, September 30). Peran aktif pemerintah Indonesia dukung industri startup dan ekonomi digital. Diunduh Oktober 25, 2016, dari Dailysocial.id: https://dailysocial.id/post/peran-aktifpemerintah-indonesia-dukungindustri-startup-dan-ekonomi-digital

Sarasvathy, S., Dew, N., Velamuri, S., \& Venkataraman, S. (2003). Three views of entrepreneurial opportunity. In $\mathrm{Z}$. Acs, \& D. Audretsch, Handbook of entrepreneurship research (pp. 141-160). Great Britain: Kluwer Academic Publisher.

Sawitri, A. A. (2016, Mei 04). BPS: Pengangguran terbuka di Indonesia capai 7,02 juta orang. Diunduh Oktober 25, 2016, dari Tempo.com: https://m. tempo.co/read/news/2016/05/04/17376 8481/bps-pengangguran-terbuka-diindonesia-capai-7-02-juta-orang

Shane, S. (2000). Prior knowledge and the discovery of entrepreneurial opportunities. Organization Science, 11(4), 448 469.

Shane, S. (2003). A general theory of entrepreneurship: The individual-opportunity nexus. Cheltenham: Edward Elgar.
Shaver, K., \& Scott, L. (1991). Person, process, choice: The psychology of new venture creation. Entrepreneurship Theory and Practice, 2(2), 23 - 45.

Someran, M. W., Barnard, Y., \& Sandberg, J. A. (1994). The think aloud method: A practical guide to modelling cognitive processes. London: Academic Press.

U.S Small Business Administration. (2016). Startups $\mathcal{E}$ high growth businesses. Diunduh Oktober 26, 2016, dari Small Bussines Administration: https://www.sba.gov/startingbusiness/how-start-business/businesstypes/startups-high-growth-businesses

Venkataraman, S. (1997). The distinctive domain of entrepreneurship research. Advances in Entrepreneurship, Firm Emergence and Growth, 3(1), 119 - 138.

Vosniadou, S. A., \& Ortony, A. (1989). Similarity and analogical reasoning. Cambridge: Cambridge University Press.

Ward, T. B. (1995). What's old about new ideas? In S. M. Smith, T. B. Ward, \& A. Finke, The creative cognition approach (pp. 157-178). Cambridge: MIT Press.

Whittlesea, B. (1997). The representation of general and particular knowledge. In K. Lamberts, Knowledge, concepts and categories (pp. 211-264). Cambridge: MIT Press. 